\title{
¿QUÉ CUENTA EL RANCHO TIJUANA? DESDE SU FUNDACIÓN Y MÁS ALLÁ.
}

\section{WHAT TELLS RANCHO TIJUANA? SINCE ITS FOUNDATION AND BEYOND.}

\section{Zulia Yanzadig Orozco Reynoso ${ }^{1}$}

\begin{abstract}
El presente artículo desarrolla la conformación histórica y social de Tijuana, Baja California, México. Abarca desde 1829, cuando le otorgan la concesión al Sr. Arguello, hasta la Tijuana de 2010, aquella ciudad que cambio dramáticamente su espacio social tras la firma del Tratado de Libre Comercio con América del Norte, para consolidarse en 'la ciudad multicultural' de México. El artículo incluye además del pasaje histórico, un análisis multifactorial de la ciudad, abarcando los ejes temáticos: desarrollo poblacional, desarrollo urbano, economía local - regional, trafico de sustancias ilícitas, y su intrínseca relación con California (Estados Unidos) y su influencia a lo largo del tiempo.
\end{abstract}

Palabras clave: Tijuana, historia, desarrollo urbano, criminalidad, frontera multicultural

\begin{abstract}
This article develops the historical and social formation of Tijuana, Baja California, Mexico. It covers since 1829, when the concession was granted to Mr. Arguello, up to Tijuana 2010, that city that dramatically changed it's social space after signing the North America Free Trade Agreement, to consolidate the 'multicultural city' of Mexico. The article includes besides the historic passage, a multifactorial analysis of the city, covering the themes: population development, urban development, local - regional economy, illicit substances trafficking, and it's intrinsic relationship with California (United States) and it's influence over time.
\end{abstract}

Keywords: Tijuana, history, urban development, criminality, multicultural frontier

\footnotetext{
${ }^{1}$ Profesora de la Universidad Autónoma de Baja California, e investigadora para "Justice in Mexico" de la Universidad de San Diego. Consultora internacional para el Economic and Social Research Council (Reino Unido). Visiting fellow para la Universidad de California, San Diego; y Fulbright fellow para el John Jay College of Criminal Justice (2016 - 2017). Maestría en Derecho por la Universidad Nacional Autónoma de México. Email: zulia.orozco.pnud@gmail.com
} 


\section{¿QUÉ CUENTA EL RANCHO TIJUANA? DESDE SU FUNDACIÓN Y MÁS ALLÁ.}

El presente texto refleja los principales acontecimientos históricos que influyeron la conformación de Tijuana, desde su fundación hasta el decenio de 2010. El documento refleja un análisis socio-histórico desde el periodo Rancho Tijuana, para posteriormente abarcar la Tijuana de la 'época dorada' y finalmente la Tijuana del 'Milenio'. Las tres etapas son distintas, pero tienen en común las instituciones estatales débiles, criminalidad, y una filosofía de consumo industrial.

El apartado denominado "Del Rancho al Pueblo Zaragoza: Frontera con el Viejo Oeste" comienza por revisar el nombramiento de la demarcación como tal; los actores centrales de la época; el origen del problema de la propiedad privada - estatal; la ausencia del Estado; y el inicio de la actividad criminal en la frontera noroeste del país por actores estatales y empresarios. Este apartado también contempla la prohibición de alcohol en Estados Unidos, que impactó económico el Rancho Tijuana.

El siguiente apartado titulado "Tijuana ¿tequila, sexo y marihuana? Su consolidación socio histórica más allá del mito", hace una reflexión en torno a la institucionalización de la corrupción y criminalidad a nivel local durante la época dorada. Se rescatan dos procesos relevantes que marcaron el desarrollo urbano de la ciudad, así como el surgimiento de nuevas familias en el poder, que ahora mismos están en ambos lados de la frontera.

El último aparatado, "Tijuana Millennium: el New York - Versión Mexicana", se concentra en los años previos y posteriores al milenio, para finalmente cerrar en la temporalidad 2000 2010. Abunda sobre densidad poblacional; las nuevas actividades económicas; los actores centrales; la participación especial de Julián Leyzaola; y finalmente enuncia una filosofía que se imprime dialécticamente, entre la ciudad y los tijuanos.

\section{DEL RANCHO TIJUANA AL PUEBLO ZARAGOZA: FRONTERA CON EL VIEJO OESTE.}

Los trazos urbanos, históricos y socioeconómicos de lo que hoy en día es la multicultural ciudad de Tijuana, inician con la intervención del soldado californio Santiago Arguello Moraga [1792-1862]. Este recibió en 1829, una extensión de tierra en Baja California por el servicio que prestó en el Presidio de San Diego, Alta California, México. Como se verá a lo largo del texto, inevitablemente la historia y la dinámica local de las Californias [Alta y Baja] se entrelazan profundamente en la microrregión Tijuana - San Diego, independientemente de la conformación geopolítica de la frontera internacional entre México y Estados Unidos. 
Antes, es importante recurrir a la historia nacional y local a manera de contextualizar y deconstruir, las principales variables que influyeron históricamente en la conformación socioespacial de Tijuana. Del tal suerte que, si nos concentramos en el año de 1829, recordaremos que España hacía el intento por invadir México independiente; mientras que el Gobernador de la Alta California, José María Echeandía [1825 - 1831 y 1832 - 1833], extendía un generoso título de concesión al soldado Arguello, por una superficie de 4,387.5 hectáreas.

El límite al norte de la propiedad era 'Mesa de Arroyo de la Cruz'; al sur 'Aguaje de la Nopalera' cerca de 'La Olla'; al este el 'Datilar', y al oeste la 'Posa de los Adobes'. Lo que alguna vez fue 'Mesa de Arroyo de la Cruz', ahora se denomina 'Mesa de Otay'; colonia dónde se localiza el Aeropuerto Internacional de Tijuana, así como la Garita con Estados Unidos. Otay, como le conocen sus residentes, se ha especializado en asuntos fronterizos, por lo que la vida cotidiana de esa colonia gira en torno a gestiones aduanales.

Por otra parte, al sur, lo que se conoció como 'Aguaje de la Nopalera', actualmente se llama 'Aguaje de la Tuna'. Los límites geográficos son el Libramiento Sur Tijuana - Rosarito, próximo a la 28ㅁ Zona Militar, y el Parque Industrial Morelos. Respecto a los restantes límites territoriales, el 'Datilar' y 'Posada de los Adobes', ha sido imposible detectar la localización geoespacial de los mismos.

La propiedad de Don Santiago Arguello era vasta; pero su riqueza se concentró aún más a partir de 1846, cuando el último Gobernador mexicano de la Alta California, Pío Pico [1801 - 1894], ratificó los derechos de propiedad ipor 10, 535 hectáreas! La nueva cifra equivale a poco más del doble de la propiedad original. La familia Arguello no se quejó, y prácticamente de la noche a la mañana duplicó su propiedad, reajustando los linderos a lo que actualmente son los municipios y localidades de: El Pinal, Playas de Rosarito, Primo Tapia, Puerto Nuevo, Tecate, Tijuana, y Valle de Guadalupe (casi esquina con Ensenada), como se aprecia en la siguiente imagen.

En el contexto nacional, México ya había tenido involuntariamente serias confrontaciones bélicas con la Corona Española (1829), la naciente potencia mundial de Estados Unidos (1836), y la Francia el Rey Luis Felipe I (1838 - 1839). Una pesadilla para cualquier país de reciente formación. Afortunadamente para éste, libró los ataques violentos de los europeos más no el de Estados Unidos, quién tras un primer proceso disfrazado de separatismo, absorbió a Texas en 1845, aumentando inmediatamente su territorio y el margen de influencia hacia México y América Latina. Estados Unidos detectó rápidamente las debilidades institucionales de su vecino del sur; de tal suerte que, no titubearon en expandir aún más su frontera hacia el oeste, y le declararon la 
guerra un año después del 'Texas affair'. La motivación real que empujó el conflicto bélico fue la visión expansionista de los norteamericanos.

Para la segunda guerra contra Estados Unidos (1846-1848), México estaba en una posición francamente debilitada y desgastada, tras los conflictos bélicos internacionales previamente señalados. De tal suerte que no pudo más, y cedió a las exigencias desmedidas de la contraparte, la cual como ya se dijo, estaba ansiosa de llegar a la costa del Pacífico. Al firmar del Tratado de Guadalupe Hidalgo [1848], México sumó a su pérdida los territorios de Nuevo México y la Alta California.

Por supuesto, éste proceso político impactó inmediatamente la vida cotidiana de la microrregión, al fijar oficialmente límites territoriales en lo que alguna vez fueron pueblos hermanos, fundados incluso por familiares directos. Ahora serían parte de culturas y países distintos, uno de los cuales se esforzaba por nacer cómo una ambiciosa potencia internacional; mientras que el otro, contaba con instituciones frágiles y fragmentadas desde el periodo prehispánico debido a factores culturales y políticos (Paz; 2015). Invariablemente, la frontera con el Viejo Oeste reflejaría virtudes y carencias, entre potencia mundial y una en vías de desarrollo.

Derivado del obligado reajuste político, económico, jurídico y social del nuevo mapa internacional (local para los residentes de la microrregión), el poder central realizó movimientos que de nueva cuenta, afectaron a la familia Arguello y por supuesto, el Rancho Tijuana. Aproximadamente una década después de la firma del Tratado Guadalupe - Hidalgo, por decreto presidencial publicado el 10 de marzo de 1857, el gobierno mexicano anuló concesiones que no contaran con el aval de las autoridades centrales. Tras el decreto, comenzaron las auditorias para comprobar la titularidad de la propiedad. Los Arguello participaron en el proceso de escrutinio realizado por la Federación, siendo Presidente Benito Juárez (1858 - 1872).

En aproximadamente 30 años, el Rancho Tijuana pasó de ser una remuneración por los servicios en el Presidio, por cierto derechos otorgados en una simple servilleta; para posteriormente ser reconocida la propiedad por el Gobernador de la Alta California, Pio Pico, quién además de extender más del doble de superficie, también le dio validez jurídica al título de propiedad original. La consumación (legalización dirían otros) la realizó el Presidente Juárez, quién otorgó el título de propiedad expedido por el Poder Central.

La situación finalmente parecía estabilizarse en el Rancho, cuando la muerte alcanzó a Don Santiago Arguello. Como la mayoría de los procesos hereditarios, automáticamente comenzaron los problemas legales e intrafamiliares; después de varios años dedicados a trámites 
administrativos, ahora era necesario actualizar los nombres de los propietarios del bien inmueble, ante la voracidad del gobierno central, empresarios extranjeros, e incluso de los propios familiares. Doña Pilar Ortega, viuda de Arguello, solicitó el traspaso del título de propiedad que ostentaba su marido quien en unos años lo recibió. Sin embargo, paralelamente al proceso señalado, lamentablemente para casi todos los Arguello, en 1863 se decretó la "Ley Juárez"(Bazán), la cual redujo considerablemente la superficie de la propiedad concesionada por el Estado Mexicano.

El Presidente Benito Juárez cambió de parecer y ahora consideraba que las concesiones para ganadería, deberían de tener un máximo de tres "sitios de ganado mayor" (3 leguas). La superficie del Rancho Tijuana era superior a la cantidad señalada, tras los ajustes "arbitrarios" que realizó el Gobernador Pio Pico, sin más respaldo que la voluntad política y la investidura de su autoridad. De tal suerte que, fue obligatorio vender parte de la propiedad del Rancho. Esa decisión se tomó en 1870 y abarcó el 50\% del total de la propiedad, que era aproximadamente desde lo que hoy es Puerto Nuevo hacía Valle de Guadalupe, y en rectángulo hacia el este. El movimiento de la transacción se realizó discretamente, porque fue dueño único. El tercer hijo de Doña Pilar, Ignacio, fue acreedor de casi 50\% de la superficie del Rancho Tijuana por 700 pesos (Piñera). El mismo año que Doña Pilar recibió el título de propiedad (1870), Ignacio recibió informalmente 5, 266 hectáreas, propiedad que no cumplió los requisitos Federales, al rebasar 3 leguas de acuerdo a la Ley Juárez.

En lo que se ponían de acuerdo los 14 hermanos Arguello, Ignacio hábilmente vendió parte de su propiedad a los integrantes del sector empresarial de la época como, Agustín Olvera, Teresa Arguello de Bandini, y Refugio Arguello de Bandini, quedándose con tan sólo con el 16\% de la propiedad que su madre le vendió (Bazán). Con el tiempo, los compradores poblaron poco a poco la zona y también hay que señalar que, quien así lo consideró pertinente, vendieron una fracción de su inmueble del cual por supuesto, no tenía titulo de propiedad. Sin embargo, el proceso de fraccionar había comenzado y no había marcha atrás. Las acciones ilegitimas de Ignacio Arguello detonaron, como consecuencia no deseada, el trazo urbano de Tijuana.

En 1879, tras el fallecimiento de Doña Pilar, los hermanos de Ignacio impugnaron la venta del inmueble debido a que el acto se realizó con dolo, y por lo tanto desde la perspectiva de los otros 14 herederos, la operación de compra / venta del terreno había sido ilegítima. El juicio se llevó años, como todos los procesos legales de la época, por lo que bajo esa condición inherente de vulnerabilidad, surgieron incidentes que pusieron en riesgo la herencia del Rancho Tijuana. Sobre ese mismo punto, la situación más compleja fue la duplicidad de títulos de posesión iavalados por 
la propia Federación! Mientras los Arguello eran los propietarios originales del terreno, el Presidente Porfirio Díaz decidió concesionar al empresario Luis Huller una porción del Rancho Tijuana (Padilla). Todavía no había una sentencia final del juicio entre los Arguello, que por cierto se llevó 10 años, cuando Porfirio Díaz retiró la concesión por no cumplir con los requisitos de la concesión, lo que según Díaz dio espacio a un nuevo propietario que sí los cumpliera.

Pasaron los años y en ese ir y venir caótico de títulos y confusión, los ahora nietos de Santiago Arguello aprovecharon para unirse y concretar un acuerdo que les beneficiará, mientras que Huller se encontraba distraído atendiendo problemas en la Península de mayor complejidad (Padilla). De tal forma que los Arguello llegaron a un acuerdo y firmaron un convenio, el cual fue ratificado el 6 de julio de 1889, por el Juzgado de Primera Instancia de Ensenada [Baja California]. El convenio que firmaron los Arguello avaló la legitimidad de la operación de compra / venta entre madre e hijo, lo que a su vez dividió en dos grandes secciones por igual la propiedad. Acordaron que los descendientes de Ignacio y los otros propietarios, serían dueños de la parte sur del Rancho Tijuana. Mientras que la parte norte (de Puerto Nuevo hasta Tijuana), los dueños serían los restantes herederos de Santiago Arguello, entre hijos y nietos (Bazán).

Mientras esto sucedía en el Rancho, California, el vecino del norte, consolidaba la figura mítica del Viejo Oeste. California desde siempre le apostó a la inmigración; la experimentación industrial; la diversidad cultural; la milicia y sobretodo, en la poderosa y mítica figura del Sheriff, aquella que ocupaba el ciudadano investido por la comunidad, para procurar seguridad e impartir justicia consuetudinaria en la localidad.

Así pues, aprovechando el éxito que tuvo el desarrollo urbano en California, primero por el descubrimiento de yacimientos de oro en San Francisco, momento histórico mejor conocido como la fiebre de oro (1849); así como por la fuerte inmigración derivada de la Guerra Civil Norteamericana (1861); y la introducción del ferrocarril a San Diego (1869), los Arguello decidieron aprovechar el boom inmobiliario al integrar al convenio celebrado entre ellos, un mapa del primer desarrollo urbano del noroeste de México denominado Pueblo Zaragoza (Piñera).

Los Arguello del norte, decidieron que la localización del Pueblo estaría a menos de un kilómetro de distancia de la frontera internacional, para aprovechar dos atractivos que a la fecha marcan la geografía, historia, y economía de la ciudad: 1) su cercanía con San Diego y, 2) el acceso a aguas termales con uso recreativo. Contrataron al ingeniero Ricardo Orozco, quién imprimió de influencia francesa el trazado y avaluó tanto del Rancho Tijuana, como del desarrollo urbano al interior del Rancho denominado Pueblo Zaragoza (actualmente la colonia Centro), "con el objetivo 
de dividir el Rancho y a la vez, comenzar la venta de terrenos por los Arguello... [las primeras ventas] datan del año de 1891" (Rivera).

El proyecto del Pueblo se echo andar y conforme pasó el tiempo, el paisaje rupestre comenzó a poblarse, teniendo en consideración los importantes factores ya mencionados sobre California. En 1900, los 242 habitantes del Pueblo Zaragoza difícilmente le llamaban por su nombre. La realidad era que se le conocía por Tijuana o Tijuana Zaragoza (Rivera). Justo en este periodo histórico, es dónde inicia la maraña de confusión, legal y conceptual, entre el Rancho y el desarrollo urbano al interior del primero. A partir de esa fecha los asentamientos irregulares serán una constante, al igual que los intereses de públicos y privados por la propiedad.

De lo anterior, vale la pena resaltar dos procesos que impactaron la conformación y desarrollo urbano de la ciudad fronteriza. El primero de ellos es, el abandono y desinterés de los propietarios del 'Rancho', no obstante que por décadas hicieron el esfuerzo por mantener la propiedad. La realidad era que para inicios del siglo XX, no había contacto de los propietarios hacia el 'Rancho'. El segundo proceso que es aún más intrigante y de gran importancia, es la lentísima y nebulosa conformación de Tijuana, como localidad con identidad jurídica/política. Si bien ya existía para aquella época la Prefectura de Ensenada, donde por cierto se firmó el convenio entre los Arguello, pasarían varios años para formalizar, y aún más para establecer formalmente un gobierno en Tijuana:

\footnotetext{
"Fraccionado el predio se dio inicio a formalizar la instalación del pueblo y en 1900 se formó la Subprefectura Política de Tijuana con su respectiva sección municipal que se dividía en ocho demarcaciones que incluían el pueblo y el rancho de Tijuana, Agua Caliente, La Joya, La Nopalera, San Antonio, Los Mochos, El Monumento, Mesa Redonda, Rosarito, El Descanso, Cueros de Venado, San Vicente, Pozo del Encino, Matanuco, Cerro Colorado, Jesús María, San Isidro, El Morro, El Carrizo, Palo Florido y Valle de las Palmas" (Martínez;2015).
}

El Gobierno Central no estaba presente localmente, básicamente porque aún era muy inestable, incluso al interior del país. Mientras que las principales potencias mundiales se confrontaban en la Primera Guerra Mundial (1914-1918), México vivía una prolongada guerra civil, conocida popularmente como Revolución Mexicana (1910-1917), a casi 100 años de su independencia nacional. De tal suerte que, mientras el sur se mataba por el poder, Tijuana se concentraba en su desarrollo turístico:

"At the beginning of the twentieth century and with the growth and development of the previous decades, Tijuana's profile as a tourist destination was well defined. Visitors came, mostly from California, to the horse races and boxing matches, to buy souvenirs, bathe in the hot springs and to gamble and drink in the bars. As it has been mentioned, the 
population was about two hundred and fifthy residents and the government structure was a sub-prefecture" (Piñera; 2013).

Más temprano que tarde, en 1911, la revuelta social alcanzó a Tijuana. La ciudad recibió a los hermanos Ricardo y Enrique Flores Magón, líderes del movimiento anarquista, el cual pretendía la no reelección, y la anulación del Estado y la propiedad privada. Con colaboración 'indirecta' del aliado norteño el Presidente Francisco Madero (1911-1913) derrotó a los caudillos (Taylor; 1995), es importante resaltar que ésta no sería la única vez que Baja California y particularmente Tijuana, arroparía a disidentes del sistema político hegemónico.

Así pues, pasaron los años de inestabilidad política nacional cuando surgió el acontecimiento histórico que influenció profundamente la historia y el desarrollo urbano de Tijuana: la ley Volstead, la cual se promulgó en Estados Unidos en 1919, tan solo un año después de la Primera Guerra Mundial y dos, de la guerra civil mexicana. Dicha ley prohibió la venta, importación, y fabricación de bebidas alcohólicas en Estados Unidos; lo que afectó una importante economía artesanal - industrial en aquél país: empresarios, empleados, y consumidores.

Al ser vecinos de San Diego, la ciudad naval más importante del Pacífico estadounidense (CNIC), las consecuencias inmediatas de dicha ley se hicieron evidentes en la Subprefectura Política de Tijuana, que iaún no era una entidad jurisdiccional!

Si ya el Rancho Tijuana era un destino atractivo para los californianos; con la ley Volstead se consolidó como una ciudad dedicada al ocio y esparcimiento. Turistas de cualquier parte de la Unión Americana visitaban Tijuana porque podían tomar alcohol y divertirse hasta el cansancio. Además de ofertar alcohol ilimitadamente y diversión, Tijuana contaba ya con instalaciones privadas para realizar corrida de toros; carrera de caballos; juegos de azar; peleas de box; hoteles casinos con servicio de aguas termales; y más.

Su fama como destino de recreación se consolidó en la historia, llegando a la cúspide de Hollywood, Chicago y hasta Nueva York. Turistas como por ejemplo Clark Gable o Dolores del Río visitaron el pintoresco paisaje semiurbano de Tijuana. Hasta criminales como Al Capone o Tom Dennison que tenían negocios en la ciudad. Al Capone construyó y habilitó al menos 2 inmuebles como destilerías y El Coronado Islands Yatch Club (Arredondo) con el fin de mantener sus actividades ilícitas (trasiego, distribución y venta de alcohol) en Estados Unidos.

Cabe señalar que lo anterior ocurría, mientras que el Gobierno Central no aportaba financieramente a la población de Tijuana porque se consideraba propiedad privada, y de menor importancia que la Prefectura de Ensenada. La ciudad generaba sus propios ingresos de los bienes y servicios que ofertaba en aquel entonces al turismo internacional, en el más amplio espectro, 
aunados a las paupérrimas aportaciones que hacía la Prefectura de Ensenada. Desde entonces. Así se organizaba Tijuana, y hacia frente a sus necesidades como comunidad, ante una situación que rebasaba por completo la capacidad del gobierno central.

Pasaron décadas para que dicho gobierno se estabilizará plenamente. Cuando lo hizo, se asomó a Tijuana. En junio de 1938, el Presidente Lázaro Cárdenas [1934 - 1940] decidió decretar la prohibición de los juegos de azar y las apuestas. Aunque no señaló cómo se financiaría los servicios públicos básicos en Tijuana; Cárdenas argumentaba que la 'naturaleza' de los casinos eran espacios para el vicio y la criminalidad (dixit). Ese mismo año expropió el celebre Casino Agua Caliente, icono de la modernidad y calidad de vida de los habitantes de la microrregión Tijuana - San Diego. Aunque el golpe fue duro, en realidad fue parcial: los juegos de azar y las apuestas jamás se detuvieron en el Hipódromo de Agua Caliente.

Era obvio, que el Presidente deseaba desterrar al cacique de Baja California Abelardo Luján Rodríguez, cercano a Plutarco Elías Calles (1924 - 1928), con el cual tuvo mala relación. Cárdenas, involuntariamente, posicionó al nuevo cacique en la ciudad. Este sería integrante del Grupo Atlacomulco. La situación anteriormente señalada evidenció: 1) la preferencia por integrantes de ciertos grupos de poder; 2) la debilidad del estado de derecho en la zona fronteriza, y 3) la endeble relación con el poder central. Más aún, no obstante la legislación, ningún mandatario en años recientes hizo el esfuerzo por regular plenamente las actividades ilícitas en Tijuana, hasta Vicente Fox (2000 -2006). Este era un doble discurso, por cierto muy descuidado, pues la época de oro del Hipódromo (1940 - 1970) estaba por comenzar.

A manera de cierre se puede señalar que, no obstante el abandono institucional del poder central, Tijuana se desarrolló rápidamente bajo el amparo de San Diego, ciudad hermana. La consolidación de ésta como destino recreativo por turistas internacionales, se hizo prácticamente sin contrapeso de la ley; de tal suerte que mientras California tenía la figura del sheriff, Tijuana tenía "más cantinas que edificios", incluso antes de la ley Volstead. De acuerdo al INEGI, Tijuana pasó de 242 habitantes en 1900, a 59,952 en 1950; y seguía sin jurisdicción y menos aún, autoridad. Debido a la ausencia de esta, Tijuana estaba próxima a forjar una leyenda negra, la cual para fortuna o desgracia, la marcaría por generaciones. ¿Acaso Tijuana se reducía a sexo y alcohol? De origen liberal y quehacer emancipado, Tijuana ofrecería mucho más.

Tijuana ¿̇tequila, sexo y marihuana? Su consolidación socio - histórica más allá del mito.

Como se mencionó previamente, Tijuana contó con infraestructura urbana destinada a la atención de turistas internacionales, que buscaban alcohol y diversión. Tan consolidada estaba la 
ciudad para esa época que, de acuerdo a los historiadores David Piñera y Gabriel Rivera, existían los siguientes bares, que precisamente le dieron la mítica mala fama a la localidad.

Tabla 1. Algunos bares en Tijuana / Zaragoza entre 1890 - 1950

\begin{tabular}{|c|c|c|}
\hline La Ballena & Blue Fox & Foreign Club \\
\hline Alhambra Café & The Turf Bar & Tijuana Bar \\
\hline San Francisco Café & Tívoli Bar & California Café \\
\hline Molino Rojo & San Diego Bar & Café de Luxe \\
\hline El Gato Negro & Scandia Barrel House & Mi Lugar \\
\hline El Caballito & El Faro & The Green Mill Bar \\
\hline El Ancla Bar & El Palacio Royal & Pullman Bar \\
\hline Villa Bar & Ming Bar & Vernon Club Bar \\
\hline The Garden Café & The Tunnel & \\
\hline
\end{tabular}

Fuente: Elaboración propia con información de Piñera, David and Gabriel Rivera (2013) Tijuana in History: Just Crossing the Border, México, Consejo Nacional para la Cultura y las Artes, p. 139.

En términos generales, el ciclo económico era el siguiente: mientras que de San Diego y sus alrededores llegaban turistas; el vino de las destilerías del Valle de Guadalupe (por eje, la casa L.A. Cetto), se distribuía en en bares y hoteles de Tijuana (por eje, Ceasar's). Para 1950, Tijuana se había consolidado como destino turístico internacional, en buena medida por qué aún no surgía Acapulco (1949), Cancún (1970), o Puerto Vallarta (1980); y los marinos y residentes de San Diego / Los Angeles estaban cercanos a la frontera.

De tal suerte que conforme se generó un crecimiento comercial - siempre dependiente de Estados Unidos-, fue necesario establecer la Cámara Nacional de Comercio (Canaco) en la ciudad, con el objetivo de que los empresarios se organizaran como bloque y protegieran ante autoridades federales cuyas políticas resultaban discordantes con la realidad local. En cuanto a las estatales y municipales, éstas entrarían en vigor hasta 1952 cuando Baja California finalmente deja de ser territorio, para convertirse en entidad federativa.

La Canaco se integró por empresarios que tenían negocios en Tijuana; muchos de estos no eran mexicanos. Algunos tenían nacionalidad japonesa, española, italiana, o americana. Con el tiempo, algunos empresarios fungieron como diputados o senadores en México, una simbiosis que se plasmó rápidamente en la urbanización de la ciudad y la vida cotidiana en la frontera noroeste del país. Un ejemplo de lo anterior es el caso de don Miguel Calette Anaya, quién era propietario del celebre bar Blue Fox, y que una vez Cárdenas decretará la prohibición de juegos de azar, Calette invirtió parte de su fortuna en la industria de pinturas que llevaban su apellido. Posteriormente el empresario ocupó curul como diputado federal; posición que aprovechó para empujar a la ciudad 
como zona libre de impuestos, con el argumento de la distancia ante el mercado nacional, lo cual es cierto.

Por supuesto, también Tijuana tuvo empresarios nacionales que invirtieron en comercios. Destacan los casos de la Compañía Eléctrica y Telefónica Fronteriza, fundada por los hermanos Barbachano; Bancaria del Pacífico, que se fundó en 1926 por los señores Miguel González, Heraclio Ochoa, Victoriano Sánchez y Arturo Guajardo. En 1927 se fundó la Compañía Aérea de Construcción y Transportes, cuyo propietario fuera el mismo General Abelardo Lujan Rodríguez, socio del Casino Agua Caliente, Gobernador de Baja California (1923 -1930), Presidente interino de la República (1932 - 1934), para ser nuevamente Gobernador de Sonora (1943 -1948). Otro de los comercios locales importantes que vale la pena recordar es La Suiza, que posteriormente, bajo el liderazgo de don Ernesto Jiménez Orozco, se convertiría en Leche Jersey. Este negocio 100\% familiar, se especializó en proveer leche a los residentes de la 'Baja'. El icónico negocio es testigo del desarrollo urbano de Tijuana, al crecer casi de la mano.

Como era de esperarse, el bono poblacional se disparó, surgiendo las primeras colonias: la Cacho - Escobedo (1928), muy cercana al Centro (1889), y la colonia Libertad (1930), esta última fundada por inmigrantes, desplazados de Estados Unidos tras la Gran Depresión de 1929. Mientras que la Cacho surgió como lotes bien trazados para venta al público (inmigrantes); la colonia Libertad surge tras la negociación entre "autoridades" y deportados, que se habían asentado originalmente en lo que ahora es la colonia La Presa, exponiendo su integridad física y la de sus familias (Piñera; 2013).

Por cierto, el asunto de la autoridad en Tijuana es un tema interesante y particularmente confuso (Piñera; 2013). Como hemos mencionado, el Rancho Tijuana fue una concesión que en 30 años se convirtió en propiedad privada. Esa propiedad a su vez, se le vinculó a litigios internos en donde el 50\% de la misma se vendió a parentela. En la parte norte del Rancho, se diseño un desarrollo urbano que se conocería como el Pueblo Zaragoza, sólo para cambiar su nombre de nuevo a Tijuana. Hasta ese momento, la 'Baja' era territorio nacional no reconocido como tal, lo que sea que signifique eso. Es confuso pero después de este proceso, el gobierno central finalmente aportó un ligero respaldo institucional, al decretar a Baja California Norte territorio, el 7 de febrero de 1931.

Nueve años más tarde, el 26 de abril de 1940, se creó el fundo legal de la ciudad de Tijuana; un paso decisivo para darle carácter jurídico a la localidad, para de ésta forma institucionalizar la relación gobierno - sociedad. Esto implicaba por supuesto un acercamiento 
político, jurídico, y administrativo entre las partes, aunque el alcance era considerablemente menor. La experiencia señaló que a paso lentísimo se institucionalización el estado de derecho en el noroeste del país.

Pasaron 12 años más para que el "acercamiento" se concretara el 16 de enero de 1952, al decretar a Baja California Norte entidad federativa, ocupando automáticamente la ciudad de Tijuana la categoría de ayuntamiento (municipio). Transcurrieron alrededor de 60 años sin que los residentes de Tijuana viviesen en una sociedad política enmarcada en con un sólido estado de derecho. Seguramente algunos problemas sociales en la microrregión se puedan explicar por ello; sin embargo, una vez entidad, la Federación, las autoridades estatales y locales tuvieron mayor presencia en la ciudad. Algunas de las ventajas de "formalizar" con la Federación, fue la capacidad de tomar decisiones a nivel local; recabar impuestos; y desarrollar políticas públicas locales.

Durante las décadas de 1960 y 1970, Tijuana desarrolló su infraestructura urbana, cultural, y gubernamental. Por ejemplo, destaca la Plaza Monumental en la demarcación de Playas de Tijuana que a la fecha opera; así como el celebre Jai Alai en la Avenida Revolución (anteriormente calle Olvera) en la colonia Centro donde se jugaba pelota vasca. El celebre Hipódromo de Agua Caliente se reconstruyó tras un incendio; éste es un actor fundamental en la conformación de Tijuana.

Por otra parte, la institucionalización fue lenta en Tijuana: comenzó a tomar presencia a través de los servicios de salud del Instituto Mexicano del Seguro Social (IMSS), que se instalaron en la década de 1970. Por otra parte, en lo que al estado de fuerza se refiere, la institución de seguridad era literalmente invisible: en 1977 Tijuana tenía sólo 7 patrullas de policía.

De acuerdo al censo de población del Instituto Nacional de Estadística y Geografía (INEGI), en 1980 Tijuana tenía una población ligeramente mayor a 461 mil habitantes. Esto quiere decir que, aproximadamente por cada 66 mil habitantes había una patrulla de policía preventivo. Señala "Don Fernando Quiroz" que todos se conocían en aquella época, por lo que el factor de cohesión era fuerte, y difícilmente la policía multaba por delitos administrativos. Por otra parte, también se construyó la Clínica 1 del IMSS, el Hospital General, y el Puente México, el cual tiene como destino final la Garita con Estados Unidos (localizada en la primera etapa del Rio). Cabe señalar que la ciudad se construyó diagonalmente, bordeando el Río Tijuana, de tal suerte que, la ciudad se dividió en 2 planos: el noreste y el suroeste.

A propósito de este ultimo punto, si bien Tijuana contó con una presa desde 1930, cuando llueve el agua baja por los cerros que rodean la accidentada ciudad, para desembocar al noroeste, 
justo donde están las colonias Playas de Tijuana (México) e Imperial Beach (Estados Unidos). El caos fluvial era tal que, el caudal de agua y lodo arrastró a su paso autos pesados (grúas, camiones), muebles, colchones, y por supuesto victimas. Durante la administración estatal de Milton Castellanos Everardo (1971 - 1977), la federación urbanizó la primera etapa, de 3, del Río Tijuana, que justo no habían concretado antes por problemas de tenencia de la tierra.

Las diversas consecuencias inmediatas de la urbanización del Río se pueden agrupar en 3 grandes bloques: 1) Desplazamiento. El desplazamiento forzoso de familias que vivían en la zona de riesgo; 2) Valor comercial. El incremento del valor catastral de las propiedades cercanas a la inmediación; y en el largo plazo 3) Tráfico. Se generaron nudos viales al tener un numero limitado de puentes para cruzar de un lado al otro de la ciudad.

Conforme se urbanizará el Río (1972 - 2005), también disminuirían las posibilidades de cruzar a través de caminos alternos. Ahora sólo se podía hacer a través de 7 puentes medianos. Las autoridades locales nunca pensaron las consecuencias que traería una cirugía mayor de concreto hidráulico a lo largo de la ciudad. A lo largo del canal, con los años se desarticuló y dividió lo que alguna vez fue un sólido tejido social, de la comunidad establecida en lo que ahora es el canal. La magna obra desencajaba del escenario natural; era una mole estéril, cuyas barreras de concreto hidráulico contenían el cauce natural del agua cuando -en un clima semidesértico- llegaba a llover con fuerza.

Así fue como Tijuana construyó su nuevo paisaje urbano, que no era de tradición francesa, con arboladas avenidas, calles rectas y glorietas como conectores. Ahora era angelino (Los Angeles), con su fuerte influencia industrial -amante del concreto hidráulico-, que lejos de ser amigable con el entorno natural y social, marcó una distancia egocéntrica e individualista con la comunidad y el medio ambiente. Marcó una distancia monumental entre el código basal: nosotros y ellos.

Paralelo al Rio, Tijuana se equipó de infraestructura urbana que mejoró la calidad de vida para los residentes. Por ejemplo, se fundó la Universidad Autónoma de Baja California (1957); el Centro de Enseñanza Técnica y Superior (1961); como ya se señaló, el nuevo Hipódromo de Agua Caliente (1965); el centro comercial Plaza Rio (1979); el Centro Cultural Tijuana (1982); y las Torres de Agua Caliente (1985), todos icónicas referencias de la ciudad.

El gobierno local estaba tan concentrado en urbanizar el Rio Tijuana, que no distribuyó proporcionalmente los recursos económicos, y hasta la atención de los asuntos públicos. Cuando menos lo pensaron, ya tenían que resolver un asunto mucho más importante que la construcción 
del canal: la masiva inmigración desordenada. Los nuevos tijuanos se establecieron en asentamiento ilegítimos, como la mayoría de los casos, ya fuera por falta de recursos o simplemente porque la administración pública de la propiedad, siempre fue caótica en la ciudad, básicamente desde su fundación.

De tal suerte que entre 1970 y 1980, a Tijuana se le conoció como cartolandia. El término despectivo hacia referencia a pequeñas casas de menos de 100 metros cuadrados, elaboradas básicamente de cartón y lamina. Eran casas precarias (des)encajadas entre los 'desmoronables' cerros arcillosos, a través de una técnica local que usa llantas recicladas. Era un paisaje dolorosamente visible a lo largo y ancho de la ciudad (específicamente en el Rio): durante años las autoridades (locales/estatales) no tuvieron la capacidad de disminuir la brecha de marginalidad social, económica y hasta ambiental.

Las victimas del desarrollo urbano del noroeste de México tuvieron que esperar hasta 3 gubernaturas, para ser reubicadas por las autoridades que en algunos casos, entregó títulos de propiedad, así como la cobertura de servicios básicos como pavimentación, drenaje, alumbrado, agua potable. La realidad de ayer y hoy es que no hay presupuesto suficiente para atender el imponente flujo inmigratorio a la ciudad, no obstante la buena predisposición de la autoridad. Desde la fundación a la fecha, la realidad supera las capacidades institucionales.

En esa época, para fortuna de México nace el complejo Cantarell, uno de los yacimientos de gas y petróleo más importantes del mundo a la fecha. La bonanza petrolera de aquella época benefició Tijuana. Ante los fuertes reajustes sociales y estructurales del país, las administraciones presidenciales de Luis Echeverría Álvarez (1970 - 1976) y José López Portillo (1976 - 1982) destinaron importantes recursos económicos al desarrollo social -de grupos vulnerables- a lo largo del país.

Particularmente durante la administración de López Portillo, Tijuana presentó ajustes interesantes en la conformación del espacio urbano. Para atender el desabasto de vivienda en muchas colonias de Tijuana, el gobierno federal invirtió montos relevantes en la construcción, y posterior oferta de casas. Casas de interés social, hasta residencias: había dinero de procedencia federal para que los médicos mandaran hacer ex profeso su casa, también para profesores de la Universidad Autónoma de Baja California, y ciudadanos de a pie que fueran derechohabientes del IMSS, podían solicitar su vivienda o crédito para pagar su casa.

El derroche fue una oportunidad para todos, y aún más para funcionarios públicos que trabajaban en la banca recién nacionalizada. Algunos de estos comenzaron por usar corruptamente 
las herramientas estatales, para hacerse de múltiples propiedades en la ciudad. Era fácil y barato comprar casas en Tijuana en aquel entonces. El beneficio fue tal que algunos incluso decidieron dejar de trabajar en el gobierno del estado o municipio (a través de quienes se 'bajaba' el recurso federal), para dedicarse a la compra - venta de inmuebles, cayendo por supuesto en prácticas de especulación. Lamentablemente no hay estadísticas oficiales respecto a los beneficiados del bono inmobiliario señalado; sin embargo, algunas familias que por ejemplo, ahora viven en las colonias 'Chapultepec', “Playas', 'Hipódromo', fueron beneficiados. Tal vez no se hicieron multimillonarios, pero si se hicieron acreedores a una mejor calidad de vida.

Derivado de esta política publica inmobiliaria 'popular', muchas personas, incluyendo integrantes de "familias socialmente reconocidas", acumularon capital financiero e inmobiliario, para posteriormente invertir en otros nichos económicos. Otros de plano optaron por mudarse a San Diego y hacer desde allá sus negocios. Como se verá más adelante, conforme se extiende la mancha urbana, crece la especulación inmobiliaria, donde la experiencia demuestra el involucramiento de actores estatales y no estatales.

Por otra parte, otro factor que influyó Tijuana profundamente fue el ajuste en el régimen cambiario y la nacionalización de la banca. De 1954 a 1976 el dólar estuvo fijo. Vale la pena recordar que en aquella época, la economía tijuanense estaba dolarizada; es decir, no se utilizaban pesos en la vida cotidiana. Hasta que en 1982, López Portillo dio un giro abrupto a la política financiera. De acuerdo a los entrevistados en esos años (1982 - 1985), las personas "avispadas" ganaban con la dramática diferencia entre el tipo de cambio libre y el controlado. "Don Jacinto", quién fuera gerente de sucursal en aquella época, confirmó que aunque no conoce casos personalmente, es altamente factible que sucediera lo anterior, tanto con los dólares, como con el oro.

Es importante recordar que en aquel entonces, no era necesario que la cuenta bancaria tuviese fondos al cobrar cheque. La 'llave mágica' para el retirar dinero era el aval del gerente de sucursal que firmaba y respaldaba, el documento financiero. Es decir, mientras el cheque estuviese firmado por el gerente -quien recordemos era burócrata- la cantidad era liberada, aunque no hubiese fondos en la cuenta. Así se compraban autos, se adquirían casas, y se echaban andar negocios.

En ese mismo punto, señala Don Fernando Quiroz que quienes fueron cercanos ha gerentes etéreos, "se presentaban todos los días [por la firma], durante varias veces al día, por varios años (los que duró el control de cambio), para retirar del banco cantidades fuertes en pesos, 
y posteriormente cruzar a Estados Unidos para cambiar el mismo monto a dólares". La dinámica no estaba concluida, sino hasta que los traficantes de moneda regresan al país para saldar la cuenta en moneda internacional, y de esta forma, obtener lucrativas ganancias debido a la política federal de control de cambio de divisa. Innumerables familias se hicieron de dólares a través de prácticas desleales, algunas de las cuales se fueron a vivir a San Diego y otras, se quedaron en Tijuana con una economía personal favorecida.

La corrupción estatal (que flotaban grosso modo en tráfico de divisas y tráfico de influencias) marcaron decisivamente el proceso contemporáneo de urbanización de la ciudad. Se desarrollaron decenas de nuevas colonias como las ya mencionadas. La urbanización de Tijuana se realizó sin respetar los procesos históricos, ecológicos, económicos y sociales de la localidad (ej. Canal del Rio). Destaca la falta de espacios públicos recreativos, destinados al ocio y diversión, como originalmente se conformó el Rancho Tijuana.

Podemos afirmar que durante este periodo:

1) La corrupción se institucionalizó localmente (ya estaba institucionalizada a nivel estatal, tras la gubernatura de Abelardo Luján Rodríguez);

2) Los intereses económicos del estado y sector privado re-estructuró Tijuana, prácticamente en una ciudad individualista, de trabajo, amante del concreto asfáltico y posteriormente del concreto hidráulico;

3) Al convertirse en una ciudad de trabajo, el flujo inmigratorio multicultural se disparó (disminuyendo su función como 'ciudad de paso') mientras que la identidad y el tejido social se desarticuló;

4) Al eliminar espacios recreativos para el ocio (espacios ecológicos, semi-urbanos), el turismo internacional se desplazó parcialmente hacia el sur: Cabo San Lucas, Acapulco, Puerto Vallarta y, algunos años después a Cancún.

5) El otro flujo de turistas internacionales optaron por divertirse con los servicios urbanizados que ofrecía la ciudad fronteriza (bares, casinos, hipódromo, prostíbulos).

A partir de 1952 Tijuana tuvo lo necesario para tomar decisiones locales; sin embargo, dicha encomienda se tomó con ligereza al no desarrollar un proyecto de ciudad que pudiese ser construida en colaboración de los distintos actores estatales y no estatales, de la microrregión Tijuana - San Diego. Si bien hay un diálogo próximo y respetuoso entre las ciudades hermanas, la cooperación internacional no ha sido lo suficientemente significativa para el beneficio de la microrregión, y particularmente de Tijuana. 
Otro punto a señalar es que, ya fuese por ambición, ignorancia o negligencia, ciertos actores sociales aprovecharon los recovecos de la política federal aplicada al ámbito local, para obtener un provecho personal. En ese sentido, la experiencia demuestra que no obstante su carácter liberal, multicultural y emancipador, el ayuntamiento no se ha caracterizado por ejercer sus funciones con transparencia y rendición de cuentas. A manera de ejemplo, la decisión de concentrarse en la canalización del Rio Tijuana. ¿¿Fue el diseño y material más apropiado para la ciudad? ¿Cuáles eran los intereses reales para hacer la magna obra?

Tijuana es un laboratorio social sui generis, que ha demostrado su inmensa capacidad de re-estructuración socio - multicultural, política y económica. Esta habilidad no se puede comprender sin San Diego, que entre otras cosas, comparte su ideología liberal - democrática. Tijuana va más allá de la mítica mala fama, y como componente de una ciudad global, apuesta a la posmodernidad. Algunos la reconocen como el "Nueva York, Versión Mexicana".

\section{Tijuana Millennium: el New York - Versión Mexicana.}

El primero de enero de 1994 entró en vigor el Tratado de Libre Comercio (TLCAN), que México celebró con Estados Unidos y Canadá. Aunque los efectos fueron varios, la correlación más evidente a nivel local fue la consolidación de Tijuana como una ciudad de trabajo, aumentando paralelamente la estancia de los migrantes en la localidad.

De acuerdo al INEGI, en 1995 Tijuana tenía 991,592 habitantes; en el 2000 registró 1,218,828; en el 2005 integró 1,410, 687 residentes; cinco años después, en el censo de 2010, se registraron 1,559,683 habitantes (imagen 3). Es decir, de acuerdo con la información proporcionada por la máxima institución gubernamental especializada en censos e información estadística del país, Tijuana recibe poco más de 100 mil nuevos habitantes cada quinquenio, cifra con la que no compite ningún otro municipio de la entidad, e incluso del país.

A manera de analogía, podemos señalar que cada diez años Tijuana le da la bienvenida a la población entera que integra el municipio de Jiutepec, Morelos (200,000 en 2010). A diferencia de otras ciudades que se desarrollaron por colonias, Tijuana cada 10 años se desarrolla e integra en la medida de lo posible, una población cercana al pueblo de Jiutepec, la cual por cierto tiene diversas costumbres, religiones, estilos de vida, valores, y en general, contextos socioeconómicos muy diversos.

Asimismo, el INEGI determinó que en 1990, el 56\% de la población en Tijuana había nacido en otra entidad federativa, e incluso otro país. Diez años después y 200 mil habitantes más, el 51\% 
de la población provenía de otro lugar. Como se puede observar, la situación no había cambiado pues 1 de cada 2 habitantes era foráneo. Al momento de escribir este libro, era complicado encontrar 3, y menos aún 4 generaciones oriundas de la ciudad. Por lo general son hasta 2 generaciones (padres e hijos) nacidos y criados en la esquina noroeste del país.

Si hacemos el ejercicio comparativo en relación a la densidad demográfica en otros lugares del país, en la misma época encontraremos que 2 municipios y una delegación compartieron dicha similitud, sin que precisamente tuviesen el mismo ritmo de crecimiento que el municipio de Tijuana. Tal es el caso de: 1) Ecatepec de Morelos [Estado de México], 2) la Delegación Iztapalapa [Ciudad de México] y 3) Puebla [Puebla].

Puebla, por ejemplo, es el caso más cercano a Tijuana. Registró 60 mil nuevos habitantes por quinquenio (Tijuana 100 mil), por lo que su curva de crecimiento es similar, aunque su densidad poblacional menor. Por otra parte, en 2010 Iztapalapa fue la demarcación local con mayor población a nivel nacional, aunque ciertamente desde 2005 su curva va hacia la baja. No obstante lo anterior, Iztapalapa tiene inmigrantes recibiendo en 5 años entre 20 y 30 mil nuevos vecinos. Es posible que, al ritmo de crecimiento de Tijuana, en 2020 ésta sea la entidad local más poblada del país, considerando incluso delegaciones (Ciudad de México).

Respecto al municipio de Ecatepec de Morelos [Estado de México], vale la pena resaltar que de acuerdo al censo de población, este fue el municipio más poblado del país en el 2010. Sin embargo, desde el 2005 su curva poblacional presentó un declive, posicionándose por arriba de Tijuana en el mismo periodo, con 100 mil habitantes. En 2015, el INEGI confirmó a Tijuana como el municipio más poblado del país al registrar 1,696,923 habitantes, frente a Ecatepec con una población total de 1,677,678.

No obstante su juventud y lejanía a todo, menos California, el municipio de Tijuana ha sido desde su fundación, un potente imán para ciudadanos del mundo. Vale la pena resaltar que durante el periodo 1995 - 2010, la población de Tijuana creció 57.29\% mientras que la de Iztapalapa creció 7\%, y Ecatepec de Morelos el 13\%. 
Tabla 2. Los municipios / delegaciones más pobladas de México 1995 - 2010

\begin{tabular}{|c|c|c|c|c|}
\hline Ciudad / Delegación & $\begin{array}{c}\text { Población } \\
\text { Total en 1995 }\end{array}$ & $\begin{array}{c}\text { Poblaciónn } \\
\text { Total de } 2010\end{array}$ & $\begin{array}{c}\text { Rango de } \\
\text { crecimiento total } \\
\text { quinquenal }\end{array}$ & $\begin{array}{c}\% \text { crecimiento } \\
\text { en 15 años }\end{array}$ \\
\hline $\begin{array}{c}\text { Ecatepec de } \\
\text { Morelos, Estado de } \\
\text { México }\end{array}$ & $1,457,124$ & $1,656,107$ & $40-50000$ & $13.65 \%$ \\
\hline $\begin{array}{c}\text { Iztapalapa, Ciudad } \\
\text { de México }\end{array}$ & $1,696,609$ & $1,815,796$ & $20-30000$ & $7 \%$ \\
\hline $\begin{array}{c}\text { Puebla, Puebla } \\
\text { Tijuana, Baja } \\
\text { California }\end{array}$ & $1,222,569$ & $1,539,819$ & 60,000 & $25.94 \%$ \\
\hline
\end{tabular}

Fuente: Elaboración propia con información del INEGI

Ahora, cómo zona metropolitana Tijuana es superada por otras, como por ejemplo la Ciudad de México, la de Guadalajara, o la de Monterrey. Sin embargo, en este punto habría que tener una visión realista y reconocer que, si bien en un marco geopolítico nacional, la Zona Metropolitana de Tijuana está conformada -según INEGI- por Tijuana, Tecate y Rosarito; como ya se comentó, la microrregión es mucho más amplia.

En la práctica (en el día - a -día de los tijuanos), una frontera internacional cruza la dinámica socioeconómica de la microrregión, que además de Tijuana, Tecate y Rosarito, abarca -de acuerdo a lo ya revisado- las ciudades vecinas de San Diego y Los Angeles. De tal suerte que al menos para Tijuana, el marco analítico - metodológico del INEGI, está limitado a una jurisdicción política, que no analiza profundamente -a través de la cooperación internacional-, a la urbe como un componente más de la ciudad global que es bajo el liderazgo de Los Angeles.

El desarrollo poblacional de Tijuana no es fortuito; tiene una relación directa e histórica con Estados Unidos. Tras la firma del TLCAN, la ciudad ya tenía una inercia de crecimiento poblacional; tan es así que pasó en 1990 de 721,819 habitantes a 1,212,232 en el año 2000, creciendo un 5.3\%, en contraste con la tasa de crecimiento de $26.2 \%$ en 1930 , cuando la Gran Depresión expulsó mano de obra que llegó a Tijuana. La industria maquiladora fue un incentivo más para mudarse al noroeste del país (tabla 3).

"Tijuana es por sí misma un punto atractivo para la población que busca mejorar sus condiciones de vida y ante la oferta de empleo derivado de la política industrial de apoyo a la industria maquiladora altamente concentrada en la frontera norte de México, se consolidó como destino para los flujos migratorios, principalmente por contar con tasas salariales más elevadas en relación con la mayoría de las ciudades del interior del país". (Hernández; 2002) 
En ese sentido, con sus respectivos alcances y límites, Tijuana fue la ciudad que por excelencia materializó el TLCAN. Si bien la frontera norte del país concentró maquiladoras frente otras ciudades, como por ejemplo Guadalajara y Monterrey; en realidad Tijuana absorbió centenares de maquilas en poco tiempo. A manera de ejemplo, en 1993, previa puesta en marcha del tratado internacional, Tijuana tenía 565 maquilas (Quintero; 1997), cifra que creció a 794 plantas industriales (Hernández; 2002) en el 2000. En 2005 Tijuana registró 819 plantas, cifra que en 2010 se redujo a 698 plantas (Carrillo; 2011), debido al contexto de violencia y corrupción imperante en la ciudad. A propósito de la industria maquiladora:

"En el noroeste, predomina la industria electrónica en ciudades como Tijuana y Mexicali con productos líderes como los televisores; es importante la presencia de plantas asiáticas (sobre todo japonesas y coreanas) que buscan el acceso al mercado norteamericano con la instalación de plantas matrices en California y maquiladoras en México".

$[\ldots]$

"En Tijuana los salarios promedio para personal no especializado en las maquiladoras ocupan un lugar intermedio entre los salarios devengados en el comercio y los servicios y trabajos asalariados en el sector informal, o en el servicio domestico". (Carrillo; 2005)

Si bien predomina la industria eléctrica, esta también se especializa en equipos médicos, automóviles, ropa y aeronáutica (Gobierno de Baja California). Esta aunque provee empleos (diría Hernández mejor pagados que en el sector informal o de servicio doméstico), estos en realidad no son los mejores pagados, y ciertamente son muy pocas las personas -en puestos estratégicos- que tienen la posibilidad de hacer una carrera exitosa en la industria maquiladora. Por lo general, el personal contratado tiene hasta la secundaria y no es capacitado más que para cumplir con su función laboral, que es ensamblar una pieza de la línea de producción. En ese sentido, aunque la industria maquiladora es un importante nodo laboral para la clase baja procedente del país, en realidad ésta no derrama una imponente economía, tanto a nivel gubernamental (a través de impuestos), como en los hogares tijuanenses (a través de salarios atractivos). 
Tabla 3. Distribución porcentual de la Población Económicamente Activa por rama de actividad, 1950, 1970, 1990 y 2000

\begin{tabular}{|c|c|c|c|c|}
\hline Rama & 1950 & 1970 & 1990 & 2000 \\
\hline Agropecuaria & 2.77 & 8.42 & 1.56 & .6 \\
\hline Extractiva & .07 & .62 & .18 & .03 \\
\hline Transformación & 21.19 & 23.70 & 28.81 & 32.51 \\
\hline Construcción & 8.89 & 7.46 & .57 & 7.87 \\
\hline Electricidad & 1.40 & .65 & 8.48 & .3 \\
\hline Comercio & 23.18 & 18.62 & 18.09 & 16.81 \\
\hline Comunicaciones y Transportes & 6.07 & 3.81 & 5.02 & 4.13 \\
\hline Servicios & 36.43 & 36.72 & 33.37 & 31.58 \\
\hline No especificado & N/A & N/A & 3.92 & 6.1 \\
\hline Total Absoluto & 17,313 & 90,382 & 261,526 & 446,339 \\
\hline
\end{tabular}

Fuente: Hernández Gómez, Emilio (2002) Desarrollo industrial y polarización socio espacial en Tijuana, Baja California. México, Universidad Autónoma de Baja California, pp. 51

Ese aspecto laboral influye la ciudad, como también lo hacen los 70 mil tijuanos americanos que cruzan diario (El Siglo de Torreón; 2013), la frontera internacional con Estados Unidos para trabajar / estudiar. Esta interacción es normal en Tijuana, y dicho flujo de personas trae consigo una derrama económica importante de dólares, los cuales se gastan en distintos sectores de la economía tijuanense (y por supuesto americana), que permite incrementar la calidad de vida de la población en general.

"La evolución de la actividad económica de Tijuana presenta un escenario donde el encuentro entre lo global y lo local adquiere matices especiales. El sector de servicios y comercio de carácter regional transfronterizo , característico del turismo, se mantiene en el oeste de la ciudad. Los trabajadores transmigrantes residen en Tijuana e incorporados en el mercado laboral de California, son cotidianos. El carácter del consumidor transfronterizo residente en ambos lados de la línea fronteriza, típico desde el origen del establecimiento urbano, no se ha perdido. Lo novedoso es la industria maquiladora impulsada hacia el este y sureste, ya que incorpora al mercado laboral otra tipología de trabajadores: los incorporados a procesos globales de producción. Esto permite pensar en una Tijuana con una dualidad económica en su referente espacial. Una parte de la ciudad conserva el carácter que da origen a su establecimiento, mientras la otra es referencia a los nuevos procesos de globalización". (Hernández; 2002)

n términos laborales, si hablamos de Tijuana Millennium no podemos dejar de mencionar al sector médico, que influye a la fecha de una forma relevante el contexto y la economía de la ciudad. Dicho sector se consolidó aproximadamente en 1995, como la capital mundial de la cirugía plástica, la cual provee servicios médicos diversos principalmente a pacientes norteamericanos, que no necesariamente radican en la microrregión Tijuana - San Diego. 
De acuerdo con El Observatorio Turístico de Baja California (Ibarra; 2014), en 2014 se detectaron 840 mil visitas anuales, misma que dejó una derrama económica por 300 millones de dólares. El periodo cercano al milenio fue importante para la poderosa industria del turismo médico en Tijuana, hasta que la violencia se hizo cotidiana y afectó dramáticamente a los profesionales de la salud, como se verá más adelante. Me adelante solamente para señalar que este será un actor relevante en el periodo 2008 - 2010, y su capacidad de influir es ha la fecha, mayúscula en ambos lados de la frontera.

A propósito de violencia y crimen organizado, es importante señalar que la violencia criminal en Tijuana no surge con los presuntos grupos criminales 'Cartel de Sinaloa' y "Cartel de los Arellano Félix", las cuales se les señala como artífices de la espiral de violencia en el noroeste de Baja California, durante la década de 1990 a la fecha. No, la realidad es que muchos años atrás, además del Gobernador Abelardo Luján Rodríguez, se tiene registrado actividad criminal (desde el enfoque moral, no jurídico pues aún no se legislaba) en las décadas de 1960 y 1970.

En aquel entonces "Reyes" traficaba en avioneta, droga procedente de Sinaloa e incluso Colombia, con destino a Estados Unidos. Señala "Don Fernando Quiroz", quien conoció a "Reyes", que éste era un hijo de familia reconocida de Tijuana, y tenía como fachada ser propietario de varios almacenes de repuestos en el norte de la República, aunque en una doble moral, "operaba de forma individual y discretamente en el tráfico de droga, puesto que en aquel entonces era más tranquilo". Enfatiza "Don Fernando" que "ni siquiera se conocía el significado de 'narcotráfico', menos se iba uno a imaginar en aquella época que el vecino estaba metidísimo en eso".

Mucho después de "Reyes", Tijuana fue escenario en 1990 de violencia criminal, porque las presuntas organizaciones criminales se "disputaban el control estratégico de la frontera noroeste del país". A manera de ejemplo, los vecinos de Playas de Tijuana llegaron a escuchar entre gritos, plegarias de victimas que, después 'aparecían' envueltos en cobijas con uso excesivo de violencia. A partir de 1994, las balaceras fueron recurrentes en el día. Las colonias más afectadas fueron Playas de Tijuana, Otay, Hipódromo, La Mesa, El Mirador, y Guaycura.

Como se verá más adelante, en esa década se generó una franca ruptura entre los auto denominados grupos criminales, 'Cartel de Sinaloa' y la 'Organización de los Arellano Félix'. Esa década y la primera mitad de los 2000, los “Arellano" implementaron la estrategia 'plata o plomo'. Paulatinamente y a través de la cooperación internacional, se aprehendieron a integrantes de la presunta familia criminal. 
Aunque la investigación se concentra en los años 2000 - 2010, el periodo de violencia más salvaje se focalizó entre 2008 y 2010. Algunos especialistas en la materia lo atribuyen a que justamente en ese momento se disputó el liderazgo de Tijuana, entre el ex 'lugarteniente' de 'los Arellano Félix', el 'Teo' [quien se alió a la organización el 'Cartel de Sinaloa'] y Luis Fernando Sánchez Arellano, alias el 'Ingeniero'. En el siguiente capítulo se abundará sobre este proceso histórico, donde participaron múltiples actores, de acuerdo a la investigación.

A manera de ejemplo, vale la pena señalar que de acuerdo a los datos proporcionados por la Secretaria de Seguridad Pública del Estado de Baja California (SSPBC), en el 2006 se registraron 314 homicidios, 30 secuestros, 164 casos de extorsión, 205 violaciones, y 29,412 robos. En 2010 se registraron formalmente 31,495 robos, $\underline{688 \text { homicidios, }} \underline{68 \text { secuestros, } 272 \text { violaciones y } 232 \text { casos }}$ de extorsión. Las estadísticas oficialmente se duplicaron en el punto más álgido de la violencia, aunque claro, el INEGI ha que la cifra negra es superior al 90\%. Tijuana tuvo una tasa de homicidios de las más altas del mundo. A continuación, la tabla 4 sintetiza los delitos cometidos en Tijuana año por año, de 2006 a 2010.

Tabla 4. Delitos cometidos en Tijuana de 2006 a 2010.

\begin{tabular}{|c|c|c|c|c|c|}
\hline Año & Homicidios & Robos & Secuestro & Violación & Extorsión \\
\hline 2006 & 314 & 29,412 & 30 & 205 & 164 \\
\hline 2007 & 310 & $\underline{40,008}$ & 14 & 210 & 108 \\
\hline 2008 & $\underline{577}$ & $\underline{42,046}$ & $\underline{92}$ & 236 & 167 \\
\hline 2009 & $\underline{556}$ & 38,073 & $\underline{95}$ & 332 & $\underline{186}$ \\
\hline 2010 & $\underline{688}$ & $\underline{31,495}$ & $\underline{68}$ & 272 & $\underline{232}$ \\
\hline
\end{tabular}

Fuente: Elaboración propia con información Secretaria de Seguridad Pública de Baja California

A diferencia de principios del siglo XX donde el Estado estaba francamente ausente en Tijuana, a comienzo del milenio no era el mismo caso. Por el contrario, incluso el Presidente Felipe Calderón (2006 - 2012) desplegó 3,296 efectivos militares en la Operación Tijuana, aunado a la Policía Federal, Estatal y Municipal. Durante el operativo, los militares estaban en toda la ciudad y al interior de las instituciones de seguridad pública. El caso emblemático, posterior a la Operación, fue el Teniente Coronel Julián Leyzaola, el cual fue nombrado Director de Seguridad Pública de Tijuana durante el periodo 2008 - 2010. 
El Teniente Coronel purgó la Policía Municipal, destituyendo los elementos que no aprobaron los controles de confianza, en tanto que los que se quedaron prácticamente duplicaron su sueldo y mejoraron sus prestaciones. Aunque se dice que bajó el índice de homicidios, secuestros y extorsiones, la realidad es que sólo disminuyó los robos un 27\% (de 42 mil a 31 mil), y los secuestros con el mismo porcentaje (de 92 a 68). Por otro lado, aumentaron los homicidios un 19\% (de 577 a 688) y las extorsiones casi un 39\% (de 167 a 232). Como se verá más adelante, más que bajar las tasas, fue evidente para los tijuanos que había llegado la autoridad para contener la violencia cotidiana. Algo que las autoridades civiles no lograron hacer.

Como se verá más adelante, en este periodo la violencia se distribuyó a lo largo de la ciudad conforme a la segregación geográfica. Ahora, algunas de las colonias más afectadas fueron El Florido, Mariano Matamoros, La Mesa, Sánchez Taboada, Cerro Colorado, Centro, Huertas, Buena Vista, entre otras que, no obstante ser espacios densamente poblados, abandonaban cuerpos mutilados de victimas; mantas con mensajes violentos; o reclutamiento masivo de los brazos más endebles del crimen organizado: adolescentes que vivían en contextos de pobreza y falta de oportunidad, algunos de los cuales estaban deseosos de acceder a una "calidad de vida" a través del 'dinero fácil', la venta de drogas, o la confrontación con armas de uso exclusivo del ejercito.

Por el otro lado, fueron las colonias de clase media - alta como Playas de Tijuana, Chapultepec, Hipódromo, Agua Caliente, La Sierra, el Murua, el Rubí, Palmas, Otay, entre otras, que abastecieron a la organización de los Arellano Félix, los celebres narco juniors, que eran jóvenes pudientes; vestidos con ropa de marca; iban al club deportivo Britania; estudiados (preparatoria / universidad); con autos de año; algunos nacidos en Estados Unidos; la mayoría egresados del celebre colegio Instituto México. La tipología recaería en personas jóvenes que no tienen carencias básicas y con amplias oportunidades de desarrollo en ambos lados de la frontera. Acá la violencia se vivía de otra forma: se especializaban en sus actividades criminales, ya fuera como francotiradores, extorsionadores, distribuidores de droga o corrupción a través de la vinculación con empresarios en San Diego y Tijuana.

Respecto ambos casos, la experiencia anuncia que algunos tijuanos tienen una doble moral, y ésta ha sido histórica desde que Cárdenas 'prohibió' los juegos de azar. Esta característica camaleónica resulta engañosa y da resultados óptimos, conforme mayor es la habilidad de la persona para mantener un 'bajo el perfil'. Los grandes capos por ejemplo, tienen la posibilidad de 'jugar' roles distintos les permite una doble moral, como también lo puede hacer un ladronzuelo de 
partes de autos que por el día es taxista; o el médico cirujano que además de operar artistas, también hace fraude a las aseguradoras nacionales e internacionales al no operar; o incluso, el empresario reconocido que cada que puede, realiza fraude fiscal y lava el dinero en el exterior. La doble moral va más allá de las mascaras (Paz, Goffman) y de las aparentes clases sociales.

A manera de cierre, podemos señalar que Tijuana es una ciudad que con tenacidad ha sobrellevado dos grandes dificultades a lo largo de su historia: 1) la ausencia del Estado y 2) la meteórica tasa de densidad poblacional - expansión urbana. Paradójicamente, su fortaleza es al mismo tiempo su debilidad: la inmigración trae consigo capital (económico, cultural) que enriquece eclécticamente la cultura local; sin embargo, el gobierno históricamente ha demostrado ineficiencia para atender la creciente demanda de los tijuanos. En este contexto, al que además sumamos una frontera internacional literalmente porosa, y lagunas en la gobernabilidad local, se ha facilitado para que actores estatales y no estatales incurran en delitos, y negocien con cualquier cosa: dólares, alcohol, sustancias ilícitas, sexo, personas, y hasta la vida misma.

Tijuana no fue siempre extremadamente violenta; como tampoco fue una ciudad estrictamente de trabajo (ciudad industrial). Más aún, ésta exigió muy poco de sus gobernantes porque con o sin gobierno, el Pueblo se sostenía mientras que el Estado era literalmente invisible. Así que en algunas décadas, Tijuana transformó su paisaje urbano, y diversificó las actividades económicas, incrementado con el tiempo su clase baja y adelgazando su clase media y alta.

El detalle está en que los ajustes no fueron integrales ni transparentes, por lo que gobernantes locales y estatales han sido señalados como corruptos a lo largo de la historia de Baja California. El individualismo - egocentrismo reflejado en la 'planeación urbana' de la ciudad, no reflejó un proyecto integral de ciudad a largo plazo. Lo anterior se refleja también en los ciudadanos que a su vez, exigen a las autoridades mediante esquemas de inmediatez y consumo industrial, desconcentrado de la naturaleza y el hombre.

El cuadro sintomático se presentó entre 2000 y 2010, siendo el periodo más salvaje de 2008 - 2010. En el siguiente capítulo el lector revisará la historia de la criminalidad en Tijuana, concentrada en la década señalada.

\section{BIBLIOGRAFÍA}

ACEMOGLU, Daron y James Robinson. Por qué fracasan los países. El origen del poder, la prosperidad y la pobreza. España, Deusto, p. 346, 2012 
ARREDONDO, Benjamin. Islas Coronado otro de los refugios de Al capone en México en: http://vamonosalbable.blogspot.mx/2009/01/islas-coronado-otro-de-los-refugios-de.html_2009

BAZÁN CRUZ, Francisco. El Ex Rancho de Tijuana, Aspectos Históricos, Jurídicos y Sociales en: http://bibliohistorico.juridicas.unam.mx/libros/2/730/39.pdf ${ }_{L}(\mathrm{~S} / \mathrm{F})$

CARRILLO J., A. Hualde y C. Quintero. 'Maquiladoras en México. Breve recorrido histórico' en: Comercio Exterior, Vol. 55, núm. 1, México, pp. 30 - 42 en http://www.colef.mx/jorgecarrillo/wpcontent/uploads/2012/04/PU292.pdf , 2005

CARRILLO, Jorge y PIÑERA, David. Baja California a cien años de la Revolución Mexicana 1910 - 2010. México, El Colegio de la Frontera Norte - Universidad Autónoma de Baja California, pp. 294, 2011

CNIC NAVAL BASE SAN DIEGO. Welcome to Naval Base San Diego en: http://www.cnic.navy.mil/regions/cnrsw/installations/navbase_san_diego.html, 2016

EL SIGLO DE TORREÓN. Tijuana, Sólo Una Ciudad Dormitorio en: https://www.elsiglodetorreon.com.mx/noticia/920334.tijuana-solo-una-ciudad-dormitorio.html , 2013

FRAGOSO, Gerardo. Zona Económica Especial: 82 años de historia en: UniRadio Noticias. http://www.uniradionoticias.com/noticias/bajacalifornia/369044/zona-economica-especial-82anos-de-historia.html , (S/F)

GOBIERNO DE BAJA CALIFORNIA. Baja California Trade and Investment en: http://www.investinbaja.gob.mx/en/profile/statistics , 2015

HARVEY, David La condición de la Posmodernidad. Argentina, Amorrortu, p. 408, 1998

HERNÁNDEZ GÓMEZ, Emilio. Desarrollo industrial y polarización socioespacial en Tijuana, Baja California. México, Universidad Autónoma de Baja California, pp. 49., 2002

HISTORY. Texas en http://www.history.com/topics/us-states/texas, 2016

IBARRA, Israel. Turismo médico deja derrama de cerca de 300 mdd a BC en El Financiero en: http://www.elfinanciero.com.mx/empresas/turismo-medico-deja-derrama-de-cerca-de-300-mdda-bc.html 2014

MARTíNEZ ZEPEDA, Jorge Ciudad. Del Rancho Tijuana a la Formación del Pueblo. Una aproximación a sus pioneros en: www.tijuana.gob.mx/ciudad/CiudaddelRancho.aspx _2015

PADILLA CORONA, Antonio. El Predio del Rancho Tijuana en: http://iih.tij.uabc.mx/iihDigital/Calafia/Contenido/Vol-IX/Numero3/ElprediodelRanchoTijuana.htm, $(\mathrm{S} / \mathrm{F})$

PIÑERA, David and Gabriel Rivera. Tijuana in history: Just crossing the border, p. 101, 2013 
PADILLA CORONA, Antonio. Ciudad. Desarrollo Urbano en: http://www.tijuana.gob.mx/ciudad/CiudadDesarrollo.aspx 2016

PAZ, Octavio. El laberinto de la soledad. México, Catedra, p. 608, 2015

PROCURADURÍA AGRARIA. Glosario de términos jurídico - agrarios. México, Romosso, p. 159, 2009

QUINTERO, Cirila. Restructuración sindical en la Frontera Norte. El caso de la industria maquiladora. México, El Colegio de la Frontera Norte, pp. 56., 1997

RIVERA, Gabriel. Cuando Tijuana se llamó Ciudad Zaragoza en: ed.elmexicano.com.mx/suplementos/identidad/79/page-11.pdf, 2014

SÁNCHEZ, Laura. Lujuria. Sexo, las 24 horas del día en Tijuana en: El Universal. http://www.eluniversal.com.mx/articulo/estados/2016/03/25/lujuria-sexo-las-24-horas-del-dia-entijuana, 2016

TAYLOR HANSEN, Lawrence Douglas. La revuelta magonista de 1911 en Baja California: acontecimiento clave en el desarrollo del sentimiento nacional entre la población peninsular norteña en Frontera Norte. México, El Colegio de la Frontera Norte, Vol. 7, Núm. 13, Enero - junio em: $\quad$ https://www.colef.mx/fronteranorte/articulos/FN13/2f13_Revuelta_magonista_de_1911_BC_desarrollo_sentimiento_nacional.pdf, 1995

TELLO, Carlos. Estado y desarrollo económico: México 1920 - 2006. México, UNAM, p. 774, 2007

UNITES STATES CENSUS BUREAU Table 1. Residence County to Workplace County Flows for the United States and Puerto Rico Sorted by Residence Geography: 2006 - 2010 en Metropolitan and Micropolitan, en https://www.census.gov/population/metro/data/other.html_2016

Trabalho enviado em 14 de outubro de 2016.

Aceito em 21 de outubro de 2016. 